\title{
Treatment of Light Brown-colored Seborrheic Keratoses with a Long-pulsed 755-nm Alexandrite Laser
}

\author{
Sung Bin $\mathrm{Cho}^{1}$ \\ Min Ju Choi' \\ Sang Ju Lee ${ }^{2}$ \\ Young Koo Kim²
}

${ }^{1}$ Department of Dermatology and Cutaneous Biology Research Institute, Yonsei University College of Medicine, Seoul, Korea

${ }^{2}$ Yonsei Star Skin \& Laser Clinic, Seoul, Korea

Received November 14, 2012

Reviced November 29, 2012

Accepted December 3, 2012

\footnotetext{
Correspondence

Young Koo Kim

Yonsei Star Skin \& Laser Clinic,

72-14 Changchun-dong, Seodaemun-gu,

Seoul 120-180, Korea

Tel: $+82-2-332-0023$

Fax: +82-2-324-0063

E-mail: yonseistar64dahanmail.net

(c) Korean Society for Laser Medicine and Surgery

(@) This is an open access article distributed under the terms of the Creative Commons Attribution NonCommercial License (http://creativecommons.org/ licenses/by-nc/3.0) which permits unrestricted noncommercial use, distribution, and reproduction in any medium, provided the original work is properly cited.
}

\begin{abstract}
Seborrheic keratoses are benign skin lesions, which present clinically as well-demarcated round to oval-shaped tumors. Laser devices used for treatment of seborrheic keratosis include ablative lasers, such as the erbium:YAG laser and carbon dioxide laser, and non-ablative lasers, such as the 532-nm diode laser, 755-nm alexandrite laser, and 532-/1064-nm $\mathrm{Nd}$ :YAG laser. Here, we report on a 77-year-old patient with light-browncolored seborrheic keratoses, which was effectively treated using a longpulsed 755-nm alexandrite laser without color enhancement. We suggested that the delivery of long-pulsed high fluence laser energy to seborrheic keratoses with protection of epidermis by an integrated dynamic-cooling device could have provided high efficacy and low risk of side effects even in light-colored lesions with few target pigments.
\end{abstract}

\section{Key words}

Long-pulsed alexandrite laser; Seborrheic keratosis 


\section{INTRODUCTION}

Seborrheic keratoses are benign skin lesions, which clinically present as well-demarcated round to ovalshaped tumors.' Seborrheic keratosis has been treated for cosmetic reasons due to its benign nature by shaving or complete excision, curettage, cryotherapy, electrodessication, chemical peel, or various laser devices. ${ }^{1-4}$ Laser devices used for the treatment of seborrheic keratosis include ablative lasers, such as erbium:YAG laser and carbon dioxide $\left(\mathrm{CO}_{2}\right)$ laser, and nonablative lasers, such as 532-nm diode laser, 755-nm alexandrite laser, and 532-/1064-nm Nd:YAG laser.

The colors of seborrheic keratosis range from skincolored or yellowish, light brown or gray brown to deeply pigmented black. ${ }^{1}$ Nonablative lasers with selective photothermolysis theoretically target the melanin pigments in seborrheic keratoses because the lack of laser-responsive pigment can result in treatment failure. ${ }^{2,3,5}$ In addition, a previous study used red marker for color enhancement in the treatment of seborrheic keratoses with 532-nm diode laser to improve treatment outcome. ${ }^{2}$ Here, we described a 77-year-old Korean patient with light-brown-colored seborrheic keratoses, which was effectively treated with long-pulsed 755-nm alexandrite laser without any color enhancement.

\section{CASE REPORT}

A 77-year-old Korean male presented to our clinic with multiple pigmented papules on the face, which had progressively increased in size and number over the past 20 years. On initial examination, the lesions were light-

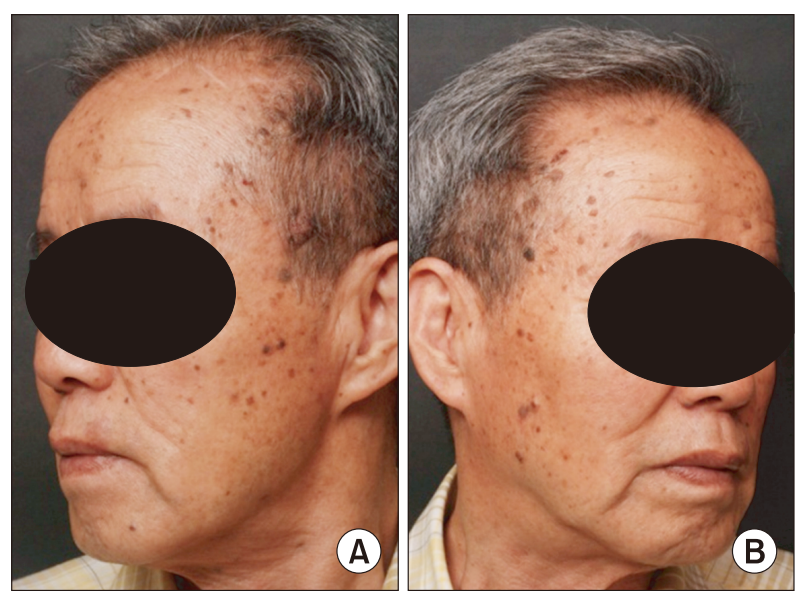

Fig. 1. (A, B) Light brown to deeply pigmented black colored multiple seborrheic keratoses on the face. brown to deeply pigmented black and he was clinically diagnosed with seborrheic keratoses (Fig. 1). He had no specific medical diseases and had no history of treatment for his facial skin lesions.

After obtaining informed consent, he was treated with two sessions of long-pulsed 755-nm alexandrite laser (GentleMax; Candela, Wayland, MA, USA) with one-month interval. For local anesthesia, a topical eutectic mixture of $2.5 \%$ lidocaine hydrochloric acid and $2.5 \%$ prilocaine (AstraZeneca AB, Södertälje, Sweden) was applied to the lesions under occlusion for one hour before laser treatment. Seborrheic keratoses were treated with non-overlapping single or double pulses with the 755$\mathrm{nm}$ alexandrite laser. Treatment fluence was 35-50 J/ $\mathrm{cm}^{2}$ using a 6-mm spot size and a 3 millisecond pulse width. An integrated dynamic-cooling device with setting of $30 / 20 / 10,0 / 0 / 20$ or $0 / 0 / 10$ was applied to cool the epidermis. Seborrheic keratoses lesions became crusted soon after the laser treatment, which were spontaneously peeled off within seven days. He was advised to avoid excessive sunlight exposure and to use a broad-spectrum sunscreen after the crusting subsided.

Most of the lesions were removed with the laser treatment and post-therapy erythema was disappeared in two weeks. Four weeks after the first treatment, the second session of long-pulsed 755-nm alexandrite laser with identical laser settings was delivered to the remaining lesions. Photos taken two months after the last laser treatment demonstrated nearly complete clinical improvement (Fig. 2). The patient was satisfied with the results and complained of no adverse effects.
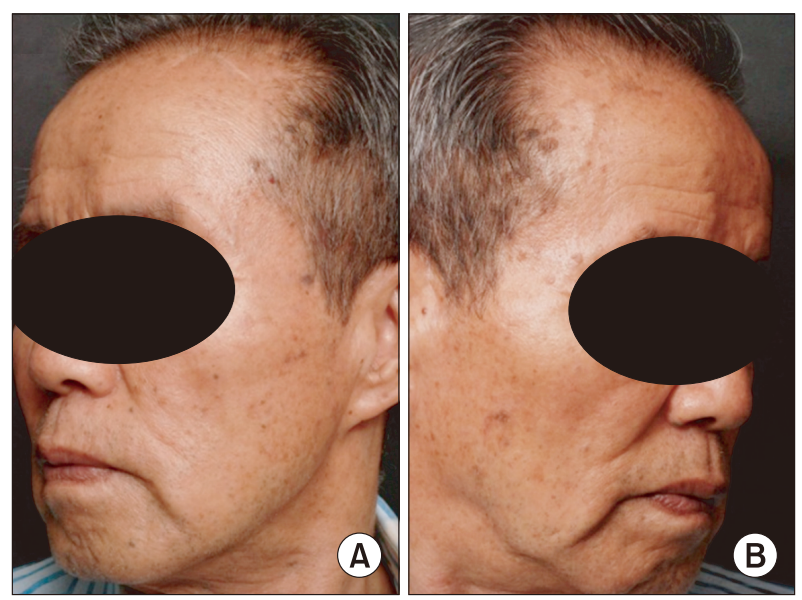

Fig. 2. (A, B) Two months after two sessions of long-pulsed 755-nm alexandrite laser treatment with one-month interval. 


\section{DISCUSSION}

Q-switched (QS) lasers have been effectively used for the treatment of various pigmented lesions, including freckles, lentigines, and melasma. ${ }^{6,7}$ However, post-laser therapy hyper- or hypopigmentation can be developed not uncommonly in Asian patients with the treatment of QS lasers, including QS Nd:YAG laser, QS ruby laser, and QS alexandrite laser. ${ }^{6}$ Laser treatment-induced postinflammatory hyperpigmentation can be developed by unwanted photomechanical effects of QS lasers, which irradiate high energy in a nanosecond-pulse duration. ${ }^{8}$

Long-pulsed 755-nm alexandrite treatment to the patients with light-colored skin presented good therapeutic efficacies on superficial pigmented lesions with minimal side effects. ${ }^{9,10}$ Comparative study with QS and long-pulsed 532-nm Nd:YAG laser in Chinese patients presented similar clinical efficacies for facial lentigines, whereas, side effects was lower in long-pulsed laser treatment. ${ }^{11}$ In addition, a prospective split-face study in Asian patients revealed that long-pulsed 755$\mathrm{nm}$ alexandrite laser for the treatment of freckles and lentigines had a lower risk of adverse events and provided effective clinical outcomes equivalent to QS 755-nm alexandrite laser.

Most of the previous studies have been used longpulsed lasers targeting the benign flat epidermal pigment lesions, especially freckles and lentigines, with in Asian patients. ${ }^{9-11}$ In the present study, we used longpulsed 755-nm alexandrite laser for multiple seborrheic keratoses on the face, which showed light brown to deeply pigmented black color. Although most of the seborrheic keratoses in our patient were elevated and had uneven surfaces, the lesions were effectively treated with two sessions of long-pulsed 755-nm alexandrite laser with no remarkable major side effects. In the present study, we found that light-brown colored seborrheic keratoses were also effectively treated with long-pulsed 755-nm alexandrite laser treatment without the help of color enhancer. We suggested that the delivery of long-pulsed high fluence laser energy to seborrheic keratoses with the protection of epidermis by integrated dynamic-cooling device could have provided high efficacy and low risk of side effects even in the lighter lesions with poor target pigments.

In this report, we demonstrated a Korean patient with light-brown-colored seborrheic keratoses, which was effectively and safely treated with long-pulsed 755-nm alexandrite laser without color enhancement. We suggest that long-pulsed 755-nm alexandrite laser with dynamic cooling device can be used for the treatment of seborrheic keratoses with various colors, ranging from light brown to deeply pigmented black, in Asian patients. However, further investigations with split-face study design should be followed to confirm our findings.

\section{REFERENCES}

1. Hafner C, Vogt T. Seborrheic keratosis. J Dtsch Dermatol Ges 2008;6:664-77.

2. Culbertson GR. 532-nm diode laser treatment of seborrheic keratoses with color enhancement. Dermatol Surg 2008;34: 525-8.

3. Mehrabi D, Brodell RT. Use of the alexandrite laser for treatment of seborrheic keratoses. Dermatol Surg 2002;28:4379.

4. Luo DQ, Yang W. A comparison of topical application of $1 \%$ tetracaine gel before and after the procedure in removal of cutaneous pigmentation with Q-switched neodymium-doped yttrium aluminium garnet laser (1064/532 nm). Photomed Laser Surg 2010;28:213-7.

5. Kilmer SL. Laser eradication of pigmented lesions and tattoos. Dermatol Clin 2002;20:37-53.

6. Ho SG, Yeung CK, Chan NP, Shek SY, Chan HH. A comparison of $Q$-switched and long-pulsed alexandrite laser for the treatment of freckles and lentigines in oriental patients. Lasers Surg Med 2011;43:108-13.

7. Cho SB, Kim JS, Kim MJ. Melasma treatment in Korean women using a 1064-nm Q-switched Nd:YAG laser with low pulse energy. Clin Exp Dermatol 2009;34:e847-50.

8. Ara G, Anderson RR, Mandel KG, Ottesen M, Oseroff AR. Irradiation of pigmented melanoma cells with high intensity pulsed radiation generates acoustic waves and kills cells. Lasers Surg Med 1990;10:52-9.

9. Rosenbach A, Lee SJ, Johr RH. Treatment of medium-brown solar lentigines using an alexandrite laser designed for hair reduction. Arch Dermatol 2002;138:547-8.

10. Trafeli JP, Kwan JM, Meehan KJ, Domankevitz Y, Gilbert S, Malomo $K$, et al. Use of a long-pulse alexandrite laser in the treatment of superficial pigmented lesions. Dermatol Surg 2007;33:1477-82.

11. Chan HH, Fung WK, Ying SY, Kono T. An in vivo trial comparing the use of different types of $532 \mathrm{~nm} \mathrm{Nd:YAG} \mathrm{lasers} \mathrm{in} \mathrm{the}$ treatment of facial lentigines in Oriental patients. Dermatol Surg 2000;26:743-9. 